\title{
SER VERITATIVO Y SER EXISTENCIAL *
}

\author{
FERNANDO INCIARTE
}

El que detrás de una única palabra, la palabra 'ser', se escondan significados tan diversos como el de predicación, el de identidad y el de existencia ha sido, según se ha dicho, una desgracia para la raza humana. Para muchos esta desgracia no es otra cosa que la metafísica. Esto, sobre todo, hace ya algunos años. Desde entonces la situación ha cambiado notablemente. Hoy día, pocos se atreverían a ver el origen de la metafísica en la confusión de los diversos sentidos del verbo 'ser'. Bien es verdad que desde Platón, si no ya desde PARMÉnides, la metafísica se habría ahorrado muchas dificultades de haber atendido de una manera más explícita a esas diferencias de significación. Pero, por lo menos ad boc, la metafísica ha hecho estas distinciones en más de un caso, incluso en muchos. $\mathrm{Y}$ esto vale incluso para el período anterior a ARISTóteles. Sin embargo, no cabe decir que las distinciones a que, de una manera explícita, ya apuntó ARIstóteles coincidan caso por caso con las que la filosofía analítica ha ido poniendo de relieve en los últimos decenios.

Cuando ArIstóteles habla del sentido múltiple del verbo 'ser', se refiere concretamente al ser según el esquema de las categorías, al ser como accidente (per accidens), al ser como acto y potencia, al ser en el sentido de lo verdadero. La diferencia tripartita de la filosofía analítica —-identidad, predicación, existencia - no aparece aquí, pues, por ninguna parte.

Por otro lado, cabe decir que desde hace algún tiempo, esta tríada ha dejado de ser el único aspecto bajo el cual la filosofía actual con-

* Conferencia pronunciada en las XVI Reuniones Filosóficas de la Universidad de Navarra, el 12 de marzo de 1979. 
sidera el ser. Otros aspectos se han venido a añadir. $\mathrm{Y}$ en el curso de esta ampliación se ha llegado a detectar otras significaciones que corresponden a algunas de las ya estudiadas por ARISTóteles. De todos modos, ni aún así se puede hablar de un estricto paralelismo. De una manera o de otra, los conceptos sobre los que opera la filosofía de la lógica modal tienen, evidentemente, mucho que ver con las distinciones aristotélicas: por una parte, del ser como posibilidad y como actualidad; y por otra, del ser según las categorías. Pero, dejando aparte la cuestión del alcance exacto de la relación entre los conceptos modales en Aristóteles y en la actualidad, así como también entre éstos y la distinción esencia-accidente, ¿qué tipo de ser podría corresponder, por poner sólo un ejemplo, en la filosofía actual, al ser que Aristótrles llamó $x \alpha \tau \dot{\alpha}$ ou $\beta \beta \varepsilon \beta \eta x o ́ s$, ens per accidens, o ser, para llamarlo de algún modo, coincidental? Aclaraciones sobre el particular serían muy de agradceer.

Sin embargo, en esta comunicación no me propongo asumir este cometido, por más que en lo que sigue pueda surgir incidentalmente (per accidens) alguna indicación al respecto. Me propongo más bien centrar la atención en algunos aspectos de lo que se ha dado en llamar ser veritativo. Es éste también uno de los sentidos que, de una manera explícita, distiguió ya ARISTóteles. Es más, el título «ser veritativo» viene a ser una traducción de lo que Aristóteles

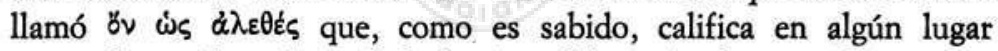
como el sentido principal de 'ser', a diferencia de otros lugares en los que da la preferencia al sentido de ser como acto y potencia. Esta diferencia de apreciación, o esta discrepancia, tal vez se deba al hecho de que por ser veritativo se pueden entender dos cosas en principio bien distintas: de un lado, la pura forma como núcleo inteligible de todo ente, ante la cual no cabe sino una aprehensión verdadera, porque, o bien se capta, o bien se deja de captar, sin que en este último caso quepa hablar de error (de esto diré algo al final); de otro lado, ser veritativo significa en Aristóteles más bien algo semejante a lo que hoy día se entiende por un hecho - y éste es el concepto tal vez fundamental de mi exposición-: el hecho de que se dé esta o aquella circunstancia. Pero antes intento rematar la alusión hecha hace un momento acerca de una aparente discrepancia en ARISTóteles en relación con el sentido veritativo del ser: tomado como algo sobre lo que no cabe error, el ser veritativo constituiría el sentido más importante en que se puede hablar de ser; tomado, en cambio, en el 
sentido de un hecho, el ser veritativo encontraría su contrapartida en lo falso y tendría por ello que ceder el primer puesto al ser como actualidad y como potencialidad.

Sea de esta preeminencia como fuere, lo que aquí nos interesa fundamentalmente es este segundo sentido del ser veritativo, aunque sea de menos importancia a los ojos de ArIsTóteles: el ser veritativo en el sentido de lo fáctico, de lo que cuenta como un hecho, etc.

Una primera aproximación nos la ha proporcionado la comparación precisamente con el concepto de hecho. Ahora bien, el concepto de hecho es un concepto cuya significación, no sólo ha variado, sino que incluso ha vacilado mucho a lo largo de la historia de la filosofía. Normalmente se entiende por hecho algo así como un trozo de realidad. Y, en este sentido vulgar, se ha entendido la palabra 'hecho' incluso en más de un tratado y en más de una corriente filosófica. Este es el caso de las filosofías que se llaman a sí mismas positivas, o que otros - a veces ellos mismoscalifican de positivistas. Cuando, por ejemplo, D'AlAmbert afirma que la filosofía es una ciencia de hechos y no de quimeras, lo que quiere decir es que la filosofía trata de cosas reales, de objetos existentes, y no de ficciones tales como las cualidades ocultas o formas sustanciales, entelequias. La concepción positivista, por otra parte muy generalizada, de lo que es un hecho, opera, por tanto, sobre la base de una manifiesta confusión entre hechos y cosas, hechos y objetos. Digo confusión porque un hecho será lo que sea, pero evidentemente no es algo equiparable a un objeto. Un hecho es siempre y en cada caso el hecho de que se cumpla tal o cual circunstancia, por ejemplo, el hecho de que esta mesa sea dura. Ahora bien, una cosa es la dureza de la mesa y otra el hecho de que la mesa sea dura. Y una cosa es una mesa dura, y otra cosa - en realidad ninguna cosa, «otra cosa» es aquí sólo un modo de decir- es el hecho de que, otra vez, la mesa es o sea dura. Que la mesa sea dura -la posibilidad de expresar en castellano un hecho en subjuntivo es muy significativa- es un hecho. La dureza de la mesa es una propiedad real, una propiedad de una cosa, y la mesa dura es una cosa, una res. Cosas todas ellas muy distintas: mientras que yo puedo tomar en mis manos una cosa dura y arrojarla contra otra cosa menos dura para destrozar la segun$\mathrm{da}$, yo no puedo de ninguna manera tomar en mis manos el hecho de que una cosa es así, de que, por ejemplo, este pupitre sea duro, y arrojar este hecho contra otro hecho, el de que, por ejemplo, el cristal de 
la ventana sea menos duro, para destrozar con éste primero el segundo hecho.

La diferencia no puede ser, pues, más clara. A ella se alude en el principio del Tractatus logico-philosophicus, cuando se dice que el mundo es la totalidad de los hechos y no de las cosas - una afirmación, por lo demás un tanto sorprendente, si se tiene en cuenta que, por lo que acabamos de ver, los hechos, a diferencia de las cosas, no pertenecen al mundo real. De todas formas hay que tener en cuenta que el mundo real, el mundo de las cosas, no es el único tipo de mundo de que podemos hablar. Basta abrir la Biblia, donde la pala. bra mundo en general no se refiere al mundo de las cosas tangibles, sino a otras cosas que tienen mucho más que ver con hechos, con estados de cosas, etc. En resumidas cuentas, un hecho es siempre y en cada caso el hecho de que tal y cual, donde 'tal y cual' está por una determinada proposición, la que sea en cada caso. Queda dicho con esto en qué sentido el ser veritativo de ARISTóteles, en su segunda acepción, al parecer, según ARISTóteles, menos importante acepción, por la que remite al concepto de hecho, mantiene una relación con el concepto de falsedad, sin quedar sustraído como en su primera acepción, de inteligibilidad de la forma pura, a la falsedad: toda proposición está, en efecto, como tal, abierta a la verdad y a la falsedad. Por eso, lo que, al principio del capítulo séptimo del libro cuarto de la Metafísica, define Aristóteles no es la verdad (o la falsedad) como tales, sino la verdad (o la falsedad) de proposiciones, en suma, lo verdadero y lo falso: verdadero es unir en una proposición lo que en realidad está unido, o al revés, o sea decir que lo que no es, no es; falso, en cambio, es decir que lo que no es, es y lo que no está separado, está separado. $\mathrm{El}$ concepto aristotélico de lo verdadero como el hecho de que tal y cual cosa, y de lo falso como lo contrario de un hecho, es decir, como la falsedad de una proposición o como proposición que no es (nicht bestehender Sachverhalt), o sea, no que no exista, sino que no dice lo que es, sino más bien lo que no es, es decir, que dice que es lo que no es, o al revés, ese concepto no es ni con mucho el único punto en el que se ve cómo en la metafísica se tuvo muy en cuenta el sentido veritativo del ser, y, en consecuencia, la distinción neta entre cosas y hechos.

Aunque mi propósito - a diferencia de lo que pudiera parecer hasta ahora - no es el de hacer comparaciones terminológicas más o menos interesantes (o más o menos aburridas) desde un punto de 
vista filosófico, me permito indicar aquí que la distinción entre cosas y hechos, entre cosas con propiedades determinadas que nos permiten manejarlas de esta o la otra manera (arrojarlas) y hechos cuyas propiedades no nos permiten en absoluto ese tipo de manipulación, pero sí otros tipos de manipulación mental, está en la base de la distinción entre proposiciones de re y proposiciones de dicto, que tanta importancia tuvo en la escolástica, y que hoy día, a través de la filosofía de la lógica modal, está volviendo a cobrar otra vez tanta atención. Con esa observación persigo dos fines: primero, aludir brevemente al hecho de que, según creo, es éste un camino por el que se podría dar con el papel que el ens per accidens (el bv $x \alpha \tau \alpha$ oupbenxós) aristotélico juega hoy día en la filosofía analítica, pero no es éste mi principal propósito; segundo y sobre todo, me propongo pasar de una vez a la parte propiamente filosófica de mi exposición, referente a la importancia para la metafísica de la distinción entre hechos y cosas, y por tanto también a la distinción entre el ser veritativo y el ser existencial.

Mi propósito en esta segunda parte es, sobre todo, interpretar con ayuda de esas distinciones un texto de Santo Tomás en relación con el espinoso problema de si el mundo pudo o no ser creado desde toda la eternidad. En éste, como en otros, el sentido veritativo del ser ('ser' como 'el hecho de que', o 'es un hecho que') juega en mi opinión un papel fundamental.

Pero antes de abordar ese texto, que es el principal, quisiera, a modo de segundo prolegómeno, remitirme a otro en el que la aplicación de nuestras observaciones preliminares sobre el sentido veritativo del ser como hecho es del todo evidente. Este primer texto (prolegómeno segundo), no se refiere al problema de la posible eternidad del mundo, sino al de la encarnación del Verbo. Al empezar por aquí, por un tema no ya sólo metafísico, sino incluso teológico, no pretendo otra cosa que hacer ver la variedad del espectro de aplicaciones de nuestra distinción entre cosas y hechos, o ser veritativo y existencial. En el artículo séptimo de la cuestión 16 de la tercera parte de la Suma Teológica, se pregunta S. Tomás si la proposición «homo factus est Deus» («un hombre se hizo Dios») es verdadera. Su respuesta es que no. La razón para esta respuesta es, sin duda, que la proposición «homo factus est Deus» a diferencia de la proposición opuesta «Deus factus est homo» («Dios se hizo hombre»), implica el error conocido bajo el nombre de adopcionismo. Que Dios se hizo 
hombre, eso sí es verdad; es un hecho al que se refiere la Biblia explícitamente. Para captar este hecho, la palabra 'Dios' tiene que ser tomada en la frase en cuestión («Dios se hizo hombre») por la segunda persona de la Santísima Trinidad, pero esto es perfectamente posible. Como se decía en la Edad Media, para ello no hay más que tomar la palabra 'Dios' en suposición personal, es decir, como estando por una, la segunda, persona, y no en suposición simple, como estando simplemente por la esencia o naturaleza divina misma (la esencia divina no se hizo hombre). Y, entonces, el que Dios se hiciera hombre no significa otra cosa sino que el Verbo se hizo carne, cosa testimoniada textualmente por la Biblia; por lo tanto, un hecho.

Pues bien, este recurso a la suposición personal -que hace posible que la frase «Deus factus est homo» sea verdadera - nada vale en el caso de la otra frase, «homo factus est Deus», ya que no sólo no es un hecho, no sólo no es el caso de que la naturaleza humana, por un imposible, se hiciera divina, cosa imposible de re, pero expresable de dicto, con tal de que se tome 'homo' y 'Deus' en suposición simple: no sólo no se da este caso, decía, sino que tampoco es el caso -aunque esta vez en principio no sería lógicamente imposible- que una persona humana, digamos Jesús de Nazaret, como supuesto puro hombre, se hiciera o se conviritiera en Dios más tarde; «más tarde», es decir, después de subsistir como fuera el tiempo que fuera. Como se ve, se trataría en este caso, en principio posible, de una afirmación de tipo adopcionista («fue adoptado por Dios»), postura condenada más de una vez por la Iglesia (por supuesto, ya antes de SANTo ToMÁs). Por tanto, la fe nos dice que la frase «homo factus est Deus», por supuesto no en suposición simple (la naturaleza humana como naturaleza divina), pero ni tan siquiera en suposición personal («un hombre se hizo Dios»), puede ser verdadera. Tan es así que, prescindiendo ahora del adopcionismo, en Jesucristo, aun siendo también perfecto hombre, no hay una persona humana, sino sólo una persona divina, que, por así decirlo, simplemente asume la naturaleza humana. Decir otra cosa sería, esta vez, adoptar una postura nestoriana. Sin embargo, por más que la frase «homo factus est Deus» no puede ser verdadera ni en suposición simple ni en suposición personal, es decir, ni tomando 'homo' y 'Deus' por naturaleza humana o divina, ni tomando ambas palabras por la persona única del Verbo; a pesar de todo, Sто. Tомás ve una posibilidad, por lo menos teórica, de darle un sentido verdadero. Esta posibilidad consiste en tomar la frase en 
sentido de lo que hoy se llama actitud proposicional; en una palabra, en tomar la palabra 'factus' no como algo de re, o que -en suposición formal - se refiere a una cosa, a la persona de Jesús de Nazaret, que, como decía, nunca fue un mero hombre, al que en un momento aconteciera tal o cual cosa (la adopción por parte del Padre), sino en tomar la palabra 'factus' de dicto, es decir, como algo que se refiere no a una cosa, sino a una frase o proposición; en tomar 'factus' por 'factum', precisamente por un hecho, concretamente por el hecho de que un hombre es Dios. En este caso la frase sería evidentemente verdadera, porque si bien no es un hecho que un hombre se hiciera $o$ fuera hecho Dios, sí es un hecho testimoniado por la Biblia que un hombre (Jesús de Nazaret) es Dios. A este respecto, el texto de STo. TomÁs es de una claridad meridiana (aquí 'factum' se podría traducir tal vez como «ocurrió que»... pero la diferencia no es decisiva): «Alio modo potest intelligi ut ly (el artículo determinado no existe en latín) factus (suposición material) determinet compositionem: ut sit sensus homo factus est Deus, idest, factum es ut homo sit Deus». Veremos, más adelante, cómo esta técnica de convertir una frase de $r e$ en una frase de dicto (en no hablar de cosas sino de hechos) es muy fructífera, tanto en STO. TомÁs como en la filosofía analítica. Si Sto. Tомás insiste, sin embargo, en la falsedad de la frase entendida como «el hecho de que», es sencillamente porque, en su opinión, la interpretación de dicto no constituye su sentido normal: «sed hic non est propius sensus harum locutionum». Por otra parte, la falsedad de la misma frase entendida de re (Jesús de Nazaret), y no referida al hecho de que la proposición es verdadera, no deja lugar a dudas: «ita quod hoc participium factus determinet absolute vel subjectum vel praedicatum. Et in hoc sensu est falsa: quia neque homo ille de quo predicatur est factus, neque Deus est factus», ya que ni el hombre de que se predica el haber sido hecho fue hecho (Cristo es desde toda la eternidad), «neque Deus est factus», ni por supuesto Dios fue hecho.

Si previamente al texto que anuncié sobre la eternidad del mundo me he ocupado de este otro, de tipo más teológico, es porque en él - a diferencia de aquél- se revela de una manera explícita el sentido veritativo del verbo ser como 'el hecho de que' prescindiendo de que también se pueda decir que 'ocurrió que': factum est ut... Esta expresión (factum est ut..., es un hecho que...) no aparece, en cambio, en el texto aludido, que es el que aquí más nos interesa. Sin 
embargo, aunque de manera explícita, STo. Tomás cuenta, también en este texto, con este mismo sentido veritativo del ser para aclarar aspectos importantes de un problema tan controvertido en su época como es el problema de la eternidad del mundo.

No me voy a ocupar aquí de particulares históricos, muchos de ellos puestos de relieve brillantemente por las investigaciones de autores recientes, tales como VAN STENBERg h EN, Mardi, SAJó, BAzán, Fioravanti, Zimmermann, Sainati y otros. Sí, en cambio, voy a aludir a un punto controvertido entre STO. TOMÁs y S. BuENAvENTURA a este respecto. Es bien sabido que ambos adoptan posturas opuestas en relación con el problema de la eternidad del mundo. STo. Tomás considera que el mundo no es eterno, nos lo dice la fe (« al inicio creó Dios el cielo y la tierra»); pero también considera que la no-eternidad del mundo - verdad de fe - no es a la vez una verdad de razón. En otras palabras: que el mundo no sea eterno no puede ser demostrado racionalmente. S. BuENAvenTURA, en cambio, cree que el inicio temporal del mundo es una verdad tanto de fe como de razón. De su comentario al libro II de las Sentencias $1 .^{2}$, art. $1 .^{\circ}$, q. 2. ${ }^{\mathrm{a}}, 6 .^{\mathrm{a}}$ ratio, edic. Quaraec H i, p. 22, da S. Buenaventura la siguiente razón para demostrar que el mundo ni fue creado ni (y aquí está la diferencia con STo. Tomís) pudo ser creado desde toda la eternidad, y lo demuestra, o pretende demostrar, con un silogismo: lo que tiene ser después de no ser (quod habet esse post non esse), dice $S$. BuEnAventua en el texto aludido, no puede ser eterno (esta es la primera premisa); el mundo tiene ser después de no ser (segunda premisa); por tanto, el mundo no puede ser eterno. La mayor, "quod habet esse post non esse» es analíticamente verdadera; según dice $\mathrm{S}$. BuENAvenTURA, «hic —entre ser después de no ser y ser eterno- est implicatio contradictoria», es imposible que se dé junto. Esto lo dice S. Buenaventura, pero lo podía decir igualmente Sto. Tomás. La diferencia entre ambos radica, en efecto, no en esta premisa mayor (lo que sigue en el tiempo no puede ser tterno), sino en la premisa menor. Que el mundo tenga ser después de no ser se desprende para Buenaventura de la creatio ex nibilo misma: «quod autem habeat esse post non esse (premisa menor) probatur sic: omne illud quod totaliter habet esse ab aliquo (es creado por otro), producitur ab illo ex nihilo». En una palabra, ser creado significa ser producido de la nada, y ser producido de la nada significa, para S. Buenaventura, - éste es el punto en el que le atacará Sto. To- 
MÁs - ser después de no ser. Precisamente contra esta deducción se dirige Sto. Tomás en el texto en cuestión, que está en la I pars. q. 46 a. 2 ad 2.

En la objeción correspondiente, STO. TомÁs repite más brevemente la deducción de S. Buenaventura: «Ego oportet dicere quod mundus sic factus est nihilo. Et sic habet esse post non esse», con lo cual se pretende demostrar el comienzo temporal (es más, jen el tiempo!) del mundo: fue creado después de la nada. También las premisas que llevan, en esta objeción $2 .^{a}$ del artículo tomista, a afirmar que el mundo procede de la nada (ergo... factus ex nihilo), no hacen sino repetir más brevemente la argumentación de S. BuENAVENTURA. La objeción reza aquí: el mundo es hecho por Dios de nada o de algo, (aut ex nihilo, aut ex aliquo). Por tanto de nada, porque no puede ser hecho de algo, como de una materia: «non est aliquo quia sic materia mundi praecessisset mundum», lo cual -aunque Sto. Tomás no lo diga expresamente aquí- contradice evidentemente el concepto de creación. S. BuENAventura viene a decir lo mismo cuando afirma que el ex nibilo de la creación no puede ser entendido materialmente, sino que tiene que ser entendido originalmente: «sed non ex nihilo materialiter, sed originaliter». Si la materia precediera al mundo, es decir, si el mundo fuera sacado de algo, que no es mundo, o que no es orden, que no es cosmos, de aliquo, no procedería totalmente de Dios. La frase buenaventuriana «ex nihilo originaliter» significa, pues, que al mundo no precede (y esto es lo importante), aparte del Creador, sino nada. Por esto, según S. Buenaventura, sí que le precede. Si no, no cabría hablar del «esse post non esse». Dicho de otra manera, la nada es, según S. BuENAVENTURA, lo único que precede al mundo.

La hipostatización del concepto de nada por parte de S. BuenAventura es, pues, evidente. Pues bien, es contra esta hipostatización contra lo que se dirige Sto. Tomás en la objeción que corresponde a la postura de S. Buenaventura. Antes de dar la respuesta de Sto. Tomás con sus propias palabras, doy su idea en otros términos. Contra lo que se dirige STo. Tomás es contra el paso de la frase «al mundo no precede nada» a la frase «al mundo no precede sino la nada»; o a la frase «no hay nada, fuera de la nada, que preceda al mundo» (un sofisma), que es como hemos interpretado, como parece evidente que hay que interpretar y como STo. TомÁs interpreta de hecho, aun sin citarlo, el «ex nihilo origi- 
naliter» buenaventuriano. La pregunta es, pues: ¿Por qué mecanismo fatal pasamos de una fórmula a la otra?, cayendo así en la hipostatización de la nada, o - a la inversa-, ¿qué condiciones hay que cumplir para no dar ese paso ilícito, de «nada precede al mundo» a «sólo la nada precede al mundo»?, paso con el que S. BuENAventura pretende demostrar el origen temporal del mundo. En términos de la filosofía analítica, la contestación a esta pregunta se podría formular así: la negación implicada aquí en el término 'nada', es una negación externa que no debe ser equiparada a una negación interna. Si se toma la precaución de no tomar la negación externa como interna, el paso ilícito de una fórmula a la otra, la hipostatización de la nada queda eliminada. Pongamos un ejemplo: contra la idea de que la existencia pudiera ser un predicado corriente o de primer orden (como diría KANT, un predicado real), se han aducido las paradojas que esta misma idea, la existencia como predicado real, llevaría consigo. Si la palabra 'existencia' es un tal predicado de primer orden, real, es decir, de la cosa (res) misma, la existencia misma tendría que ser una propiedad de esa misma cosa; pero es evidente que una propiedad no puede ser adquirida por un sujeto aún no existente. Adquirir la propiedad de la existencia presupondría la existencia de un sujeto anterior a su propia existencia, lo cual es evidentemente paradójico, por no decir imposible. (Algo así como la $2^{\mathrm{a}}$ vía de Sto. Tomás).

Me permito hacer ver esta paradoja en otros ejemplos, que no son tan imposibles: proposiciones existenciales tales como «Sócrates ya no existe» o «Sócrates no existía aún en el siglo v», «Sócrates ha dejado de existir», etc. (perder la propiedad de la existencia ya no es tan imposible). La negación interna hace referencia de re a algo que no tiene o que le falta a la persona de Sócrates. Pero si Sócrates no existe, se dice, es imposible que tenga o que deje de tener nada en absoluto, y menos, si cabe, la propia existencia. Esta por lo menos extraña, si bien en el caso de la pérdida de la existencia al revés de la adquisición, no imposible situación, desaparece sin embargo (y es el punto importante), en el momento en que interpretamos la negación únicamente como negación externa. La frase se convierte entonces en una proposición no sobre una cosa (de re), sino sobre otra proposición (de dicto). El resultado es una frase en que, junto al ser existencial que no da ya lugar a paradoja alguna, con lo cual se puede admitir que la existencia sea un predicado real, aparece también 
el ser veritativo, «el hecho de que...». Entonces, lo que decimos con negación externa, que es la que aquí hay que aplicar (como veremos que aplicará Sto. Tomás) es: «no es ya verdad que Sócrates exista», o "no es ya el caso que Sócrates exista». La diferencia entre ambas interpretaciones se ve más claramente si, mediante dos frases distintas, hacemos resaltar la relación temporal aquí implicada: «primero Sócrates existía», «después dejó de existir», es decir, «después Sócrates no existía». La paradoja de una negación interna, o de $r e$, de la existencia, paradoja que sigue aquí en pie, desaparece por completo si decimos: «primero era el caso, el hecho, de que Sócrates existía», «después dejó de ser el caso (o, no era ya más el caso) de que Sócrates existiera». La negación no va con la existencia ni con Sócrates. 'Existencia' sigue siendo aquí un predicado real de un sujeto, pero no aparece ya como expresión de una propiedad que ese sujeto pueda perder, o incluso (que es lo auténticamente paradójico) adquirir.

Pues bien, precisamente este procedimiento por el que desaparecen las paradojas del ser existencial como propiedad que una cosa puede tener o dejar de tener, como predicado real, es el mismo que Sto. Tomás utiliza en la respuesta a la argumentación de S. BuenaVENTURA ${ }^{1}$. Cito el texto de esa contestación literalmente: «Illi qui ponerent mundum aeternum, dicerent mundun factum a Deo ex nibi$l o$, non quod factus sit post nihilum (...), sed quia non est factus de aliquo» (negación externa). Traducido: "Quienes dicen que el mundo es eterno, dicen con ello que el mundo fue hecho por Dios de la nada, pero esto no quiere decir que fuera hecho después de la nada, sino que no fue hecho de algo» (negación externa). La solución positiva que se encierra en esta última frase («sed quia non est factus de aliquo»), cuyo sentido viene dado a su vez por el sentido veritativo del «est» en el «est factus». Antes de explicarlo conviene darse cuenta de que aquí nos encontramos con la misma distinción entre negación externa e intera con que la filosofía analítica resuelve las

1. Esto es aquí lo único que nos interesa, ya que es más que dudoso que -atendiendo a la diferencia de funcionamiento entre nombres propios y pronombres demostrativos - surja efectivamente esa paradoja en el caso de dejar de existir. De lo que no cabe duda, en cambio, es que el procedimiento empleado aquí para eliminar la real o presunta paradoja es necesario para evitar el error de S. Buenaventura. 
paradojas, existentes o no existentes, de la existencia como predicado de primer orden, como predicado real. Leída en el sentido de una negación interna (o de re), la frase «el mundo fue hecho por Dios de la nada» se podría entender en sentido buenaventuriano, como si el mundo pudiera adquirir la propiedad del ser existencial sin tenerla, o como si algo que no existe pudiera adquirir una propiedad. $\mathrm{O}$, para poner la paradoja de la existencia temporal más de relieve, antes incluso de tener esa propiedad de la existencia, a cualquier propiedad. Leída en cambio en el sentido de una negación externa (o de dicto) no cabe entender la frase como afirmación de semejante absurdo. No es que le precediera la nada, ni tan siquiera su propia nada, no es algo hecho de nada, no es el caso que algo fuera hecho de la nada (hipostatización de sí misma), sino que no fue hecho de algo. La palabra 'nada', proclive a la negación interna, a la negación de re, y con ello a la hipostatización de la nada, queda así eliminada y sustituída por la palabra 'algo', cuya negación no puede ser más que externa: "no es el caso que el mundo fuera hecho de algo».

La solución de STo. Tomás consiste en resumidas cuentas en decir: la proposición «el mundo fue hecho de algo» es falsa. Aquí, a diferencia del texto sobre la Encarnación del Verbo, la palabra 'hecho' no remite al concepto de hecho como distinto del de cosa, sino que es parte del predicado real (de re) «fue hecho de algo». Pero ese concepto central de hecho está encerrado en el sentido claramente (aunque negativamente) veritativo de la cópula: «non est de aliquo» significa "no es el caso», «no es el hecho de que», etc.

Aquí se ve, y no otro era mi propósito, cómo los instrumentos conceptuales de la filosofía analítica pueden servir para aclarar cuestiones debatidas por la metafísica, incluso medieval, como las referentes al fenómeno del averroísmo latino, etc. ${ }^{2}$. Pero esto no quiere

2. Esto no vale sólo para Santo Tomás. Tan es así que la solución que acabamos de estudiar procede incluso de SAN ANSELMo en el capítulo VIII del Monologio. SAnto Tomás mismo se refiere a él cuando en el tratado De aeternitate mundi contra murmurantes aborda el mismo problema. He aquí sus palabras: «Nunc restat videre an repugnet intellectui aliquid factum nunquam non fuisse propter quod est necessarium sit non esse eius esse duratione praecedere, propter hoc quod dicitur ex nibilo factum esse. Sed quod hoc in nullo repugnet, ostenditur per dictum Anselmi in Monologio, cap. VIII, exponentis quomodo creatura facta dicatur ex nihilo: 'Tertia, inquit, interpretatio, qua dicitur aliquid esse 
decir que, para llegar a estas aclaraciones, haya que aplicar a la metafísica medieval instrumentos ajenos a ella misma, sino que en muchos casos basta aplicar sus propios métodos analíticos redescubiertos en parte por la filosofía analítica actual.

De todos modos no se puede decir que con esta solución STo. Tоми́s resolviera ya, ni mucho menos, todos los problemas de la eternidad, o demostrabilidad o no demostrabilidad de la eternidad del mundo. Es más, el texto citado cae (en relación con la verdad de fe; no con la proposición de razón del juicio temporal del mundo) en las paradojas de la negación interna referentes al ser existencial, que -desde una postura estrictamente filosófica- STo. Toмás mismo había superado tan eficazmente como hemos visto. Por otra parte, la cuestión de la posibilidad, aunque puramente filosófica o de razón de una creación ab eterno con los problemas de las series infinitas de acontecimientos, etc., permanecen aún en pie después de esta solución a un problema parcial. Y lo mismo cabe decir de los problemas, metafísicamente tal vez los más importantes, del concepto de la generación y la corrupción en relación con el concepto de adquisición o pérdida del ser existencial, por ejemplo de la vida. Estos problemas entrañan entre otros el del estatuto necesario de las formas puras y, con ello, sobre todo el de la inmortalidad.

Para completar algo mi exposición voy a referirme brevemente a algunos problemas que están en inmediata relación con los que hasta ahora he tratado aquí. Me refiero, en primer lugar, a algunos pocos conectados entre sí y que surgen a propósito de la demostración de la existencia de Dios, no a la demostración misma, que para eso no hay tiempo.

Para ir más rápidamente empiezo con un ejemplo. La primera cuestión que aquí se presenta es la de si una demostración es necesaria ya que Dios podría ser de por sí evidente, per se notum, y enton-

factum de nibilo, est cum intelligimus quidem esse factum, sed non esse aliquid unde sit factum. Per similem significationem sic dici videtur, cum homo contristatur sine causa, dicitur contristatus de nullo. Secundum igitur hunc sensum, si intelligatur quod supra conclusum est, quia praeter summam essentiam cuncta quae sunt eadem ex nihilo facta sunt, id est non ex aliquo, nihil inconveniens sequetur'. Unde patet quod secundum hanc expositionem non ponitur aliquis ordo ejus quod factum est ad nihil, quasi oportuerit illud quod factum est nihil fuisse et postmundum aliquid esse». 
ces toda demostración sería superflua: bastaría captar el concepto de Dios para — como en el argumento ontológico- captar a la vez su existencia. Y lo mismo se deduce del hecho de que Dios es nuestra felicidad, a la cual todos tendemos por naturaleza, cosa que no haríamos si no le conociéramos de antemano; o del hecho de que Dios es la verdad y que sabemos - por las contradicciones inherentes al escepticismo- que la verdad no se puede negar, etc.

A todo esto que pretende demostrar que una demostración de la existencia de Dios no es necesaria, Sto. Tomás responde que hay que distinguir entre lo evidente en sí mismo y lo evidente para nosotros (per se notum quoad se y per se notum quoad nos). Y para explicarlo pone el ejemplo a que me refería. Yo puedo ver venir a Sócrates, sin saber por ello que Sócrates viene. O, como dice STo. TомÁs: «cognoscere venientem, non est cognoscere Petrum, quamvis sit Petrus veniens» ( $S$. Th. I q 2 a 1 ad 1$)$. Hay pues, que distinguir entre la frase: «veo a Sócrates que viene» (video - cognoscoSocrates venire) y la frase: "veo que Sócrates viene». En el primer caso lo que veo o conozco es un objeto, en el segundo es una proposición. El primer caso tiene pues que ver más bien con el ser como existencia, el segundo más bien con el ser como hecho o con la verdad de una proposición, y por lo tanto, más que con el hecho de conocer, con el de saber. Saber es siempre saber que... Yo no puedo saber a Sócrates pero sí conocerlo o verlo.

Las dificultades que se derivan de no hacer esta distinción son enormes y en gran parte bien conocidas ${ }^{3}$. Una parte no despreciable de estas dificultades son las relacionadas con lo que podríamos llamar sustancialismo, cosificación o reificación, por ejemplo la de las

3. Antes de terminar apuntando a estas dificultades, me permito una observación sobre la importancia metafísica que para la filosofía analítica tiene esta distinción entre «per se notum quoad se» y "per se notum quoad nos». El profesor Dummett considera que el problema fundamental de la metafísica es el de ia confrontación entre realismo e idealismo. A este respecto ha hecho notar que la distinción tomista entre lo «per se notum quoad nos» y lo «per se notum quoad se» corre paralela con la polémica actual entre lógica clásica y lógica intuicionista en torno al principio de tercio excluso. De todos modos considera que el paralelismo habría que investigarlo detenidamente, cosa que aquí no podemos hacer. Algunas de estas cosas las he expuesto en un artículo traducido al español en El reto del positivismo lógico. Creo, en efecto, que en la confrontación realismo-idealismo se trata del problema fundamental de la me- 
ideas platónicas, proveniente, según parece, o por lo menos favorecido por el hecho de que, en griego, saber (ot $\alpha \alpha$, sé) se deriva de

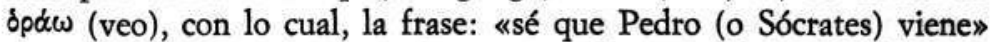

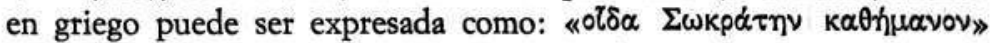
que suena a «sé a Sócrates (objeto reificado, cosificado) que viene»,

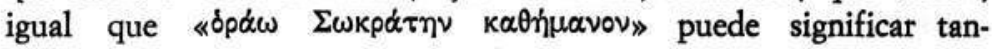
to «veo a Sócrates que está sentado» como — cosa, según hemos visto en STo. Tомás, totalmente distinta- «veo que Sócrates está sentado".

Es fácil de imaginar las consecuencias a que ha conducido esta equivocación entre saber y conocer, savoir et connaître, wissen y kennen, (en inglés, como es sabido, la cosa es más compleja), en la metafísica de corte platónico. Y es fácil de imaginar hasta qué punto ARISTóteles tuvo que ir a contrapelo del idioma griego para hacer su crítica de las ideas platónicas. Estos son temas que la filosofía analítica ha expuesto por extenso empezando por el argumento del tercer hombre ( $\tau \rho l \tau \circ \varsigma$ \& $\alpha \theta \rho \omega \pi \% \varsigma$ ).

Es bien sabido cómo Aristóteles pone fin aquí al regreso indiscriminado tanto por él, como por Platón. De los dos presupuestos que conducen a ese regreso (el de la no-identidad de cosa e idea, según la cual lo significado en el predicado de una frase elemental es distinto del sujeto de ese predicado: 'hombre' distinto de 'Pedro'; y el de la autopredicación, según la cual el predicado es a la vez sujeto de sí mismo: el hombre es un hombre, la justicia es justa, etc., con lo cual, en este segundo plano se repite de nuevo la no-identidad). ARISTóteles rechaza el primer presupuesto; Sócrates es lo mismo que hombre, signifique esta identidad ( $\mathrm{y}$ a la vez predicación, etc. - ese es el problema-) lo que sea. De este modo no necesita habérselas ni tan siquiera con el segundo presupuesto. Más difícil es ver como Platón mismo evita el regreso. Lo único claro es que él no rompe con el primer presupuesto. Entonces le quedan abiertos sólo dos caminos: el primero es interpretar frases como «el hombre es un hombre» o «la justicia es justa» no como frases predicativas

tafísica, y que la filosofía analítica está contribuyendo en gran medida al esclarecimiento de los datos en cuestión. No necesito más que citar la discusión sobre el llamado esencialismo aristotélico desde Quine hasta Kripke. 
-que es lo que literalmente (de virtute sermonis) son-, sino como (secundum intentionen autoris) de identidad. Yo creo que la doctrina platónica tanto de la participación como de la semejanza requiere más bien, o en todo caso, el segundo camino. Según él, las propiedades que predicamos de las cosas no son comunes a éstas y a las ideas, no tanto porque esas propiedades —eliminada la autopredicación- no pertenezcan a las ideas, sino porque no pertenecen a las cosas.

Los ejemplos de Platón son bien elocuentes: las cosas son a las ideas lo que las sombras y reflejos a las cosas. Bien mirado, esto significa: las cosas no son semejantes (similia) a las ideas, del mismo modo que ni la sombra de un hombre es un hombre ni el reflejo de un objeto rojo —en un espejo- es él mismo rojo.

A esto se podría objetar: entonces ¿por qué habla Platón - a pesar de esto- de semejanza, mímesis, similitudo? La respuesta es bien sencilla: no a pesar de esto, sino precisamente por esto, habla Platón de semejanza: las cosas no son, según Platón, semejantes (similia, ö $\mu \circ \iota \alpha)$ a las ideas, sino que son estrictamente nada más que

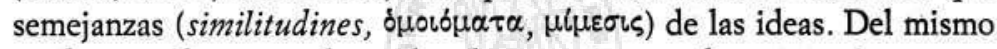
modo que el retrato de un hombre no tiene nada en común con un hombre (a no ser equívocamente), sino que es sólo eso: la imagen de... un hombre, o que el reflejo de un objeto rojo no es él mismo rojo: no es un reflejo rojo, sino un reflejo de rojo.

Yo creo que esta solución al argumento del tercer hombre, que desde el punto de vista ontológico —entendiendo por ontología la doctrina del esse naturale, del ser existencial en un sentido distinto al del cuantificador de existencia- es completamente falsa, tiene gran importancia; y es incluso verdadera desde el punto de vista de la metafísica del conocimiento, o si se quiere del esse intentionale. El concepto como signo formal, según decían los escolásticos tardíos, es precisamente esa pura imagen de (no imagen, sino imagen de...; en esto consiste su intencionalidad), reflejo de, sin ser él mismo nada de aquello de lo que es pura semejanza; con otras palabras: sin ser él mismo nada de aquello de lo que no es más que semejanza; y precisamente por ser pura semejanza es por lo que no es semejante.

La relación con nuestro tema es la siguiente: el ser como 'el hecho de que...' requiere una operación no sólo inmaterial, sino tal que supere todo lo corporal. El ser veritativo que, como dice STo. Tоми́s, es una operación intelectual, la compositio o divisio del juicio, que 
supera radicalmente todo lo corporal y todo lo animal. Y lo mismo vale decir del ser intencional como característica del conocimiento intelectual, con una sola diferencia: mientras que el ser veritativo está en relación con el ser existencial en el sentido del cuantificador existencial («Deus est» = «haec propositio est vera», «es un hecho que...», etc....), el ser intencional (el modo de ser intencional habría que decir) está en cambio en relación con el ser existencial en el segundo sentido de éste, en el sentido en que el vivir es el ser de los vivientes. No tiene por todo esto nada de extraño que Sto. Toмás para demostrar la inmortalidad del alma, recurra a esa característica de la operación del alma humana por la cual no es nada de las formas corporales - no es nada semejante, simile, a ninguna de ellas- pudiendo de este modo ser imagen de, similitudo, de todas ellas.

Mi exposición ha tocado sólo un par de puntos, pero creo que es interesante centrar la atención en dos puntos muy precisos para ver las virtualidades de los métodos analíticos también en relación con la metafísica, incluso medieval. 